\title{
Networks of Violence: Predicting Conflict in Nigeria ${ }^{\text {tr }}$
}

\author{
Cassy Dorff ${ }^{\mathrm{a}}$, Max Gallop ${ }^{\mathrm{b}}$, Shahryar Minhas ${ }^{\mathrm{c}}$ \\ ${ }^{a}$ Department of Political Science, University of New Mexico, Albuquerque, NM 87106, USA \\ ${ }^{b}$ University of Strathclyde, Glasgow, 16 Richmond St., Glasgow, UK G1 $1 X Q$ \\ ${ }^{c}$ Department of Political Science, Michigan State University, East Lansing, MI 48824, USA
}

\begin{abstract}
Civil conflicts are complex: multiple warring parties compete for control of territory both against each other and the government. These processes are often dynamic; changing over time and space. In this study, we embrace these complexities through a network based approach. By considering important relational patterns, such as reciprocity and transitivity, and tying them together with existing theoretical developments in the conflict processes literature, we answer the question of 'who fights whom and when' during civil conflict. Further, using the case of Nigeria, we offer novel theoretical insights about how the entrance of a new, aggressive actor can decisively alter the trajectory of conflict. In addition, we show that our approach is better at predicting 'who fights whom and when' in an out-of-sample context than extant approaches.

keywords: network analysis; civil conflict; political violence
\end{abstract}

\footnotetext{
"Alphabetical order signifies equal authorship, all mistakes are our own. Supplementary material for this article is available in the appendix in the online edition. Replication material and instructions are available at https://github.com/s7minhas/conflictEvolution and in the JOP Data Archive on Dataverse (http://thedata.harvard.edu/dvn/dv/jop).
}

Email addresses: cassy.dorff@unm.edu (Cassy Dorff), max.gallop@strath.ac.uk (Max Gallop), minhassh@msu.edu (Shahryar Minhas) 


\section{Introduction}

Who fights whom during civil conflict? Historically, efforts to understand violence between armed actors during civil conflicts focus on explaining why an armed actor violently mobilizes against the government. But the rebel-government paradigm is limited, as evidenced by the growing number of scholars who now theorize about the implications of multi-party civil wars (Cunningham, 2006; Akcinaroglu, 2012). Despite these advances, these studies are rooted in a dyadic research design, which examines pairs of relationships as independent phenomena and does not consider conflict between actors as a part of an interdependent conflict system. Because of this, current research has yet to provide a full consideration of the interconnected multi-actor dynamics that characterize recent examples of intrastate conflicts; a notable restriction not only given recent theoretical developments in the literature but also considering that by 2003 over $30 \%$ of ongoing civil wars involved multiple dyads in conflict with one another (Harbom et al., 2008).

In this study we explain how overlooking interdependence in civil wars leads to a misrepresentation of the full story of who fights whom during violent conflict. Recent history highlights this reality: in Syria, the entry of ISIS led to an increase in violence between pro-Assad forces and a number of armed actors in the region (Beauchamp, 2014; Schmitt, 2018). In Mexico, the rise and fall of the aggressive and powerful Sinaloa Cartel generated violence between other drug trafficking organizations across the country (La Rosa $\&$ Shirk, 2018). Similarly, understanding the path of violence between the Revolutionary Armed Forces of Colombia (FARC) and government forces is incomplete without a careful examination of the FARC's violent clashes with right-wing paramilitary groups Alesma. 2015). Without research based on both theoretical and empirical considerations of interdependence, we miss how interactions between one pair of actors can affect other actors across the system. Further, as we show in this study, ignoring interdependencies generates 
inaccurate predictions about the occurrence of conflict, and, critically, leads researchers to misidentify which actors are most likely to be involved in violence during a conflict.

We argue that an investigation into the dynamic, complex relational structure of armed actors is needed to understand who fights whom during intrastate conflicts. Our position is founded on scholarship concerned with the evolution of conflict processes, such as research by Tilly (1985) and Moore (1995). Importantly, these scholars suggest that group-level attributes of armed actors only partially explain armed group behavior and that the interactions between groups over time can provide a more complete insight into why actors fight one another. We demonstrate the value of this perspective by showing how accounting for group level interactions generates a more complete understanding of conflict.

To systematize the interactions between armed actors, we conceptualize armed actors and battles as nodes and linkages in a network wherein the actors and their relationships change over time. This framework allows us to estimate the relationships that evolve between actors within a conflict network in order to predict the occurrence of battles between groups. We employ this network approach in order to investigate civil conflict in Nigeria. The network based approach significantly outperforms traditional dyad-group approaches at predicting the occurrence of battles between groups in an out-of-sample context in the case of Nigeria.1 Our findings yield theoretical implications for the study of civilian victimization and conflict occurrence, as well as insights about how the entrance of particularly aggressive actors can decisively alter the trajectory of conflict.

\footnotetext{
${ }^{1}$ In the appendix, we show that our model also outperforms machine learning classifiers such as random forests.
} 


\section{Strategic Fighting and Network Emergence}

In this study, we investigate the formation and evolution of what we term the civil conflict network. This network is the product of strategic actions by both government and armed non-governmental actors. Below we discuss how this network emerges from armed actors' motivations and sources of power, what we gain by understanding relational patterns such as reciprocity and transitivity, and how actor composition influences violence across the civil conflict network overtime.

To understand the emergence of the conflict network, it is useful to start by looking at the motivations of the actors that make up this network - the government and rebel groups. We follow Collier \& Hoeffler (2004) in claiming that rebel actions are driven by a combination of material factors (the desire to gain additional resources, rents, or otherwise enrich the group and its leaders); and ideological factors-the desire to change public policy and shift the benefits towards particular economic, social, ethnic or religious groups (see also Gurr, 1970; Regan \& Norton, 2005; Bodea \& Elbadawi, 2007) !2 Note that this is not an either or distinction. Groups are often motivated by both a desire for resources and policy changes, but some groups value ideology more than material goods, and vice versa. Importantly, it is quite difficult to observe the mix of motivations for an armed actor. Conversely, the government is motivated principally by the desire to remain in power and secondarily to enrich themselves and their winning coalition Bueno de Mesquita et al., 2005; Goemans, 2000; Acemoglu \& Robinson, 2001).

These motivations provide incentives for groups to attack other armed groups. This can manifest as conflict between one rebel group and another, or as fighting between the government and non-state armed groups. A rebel group that is motivated by re-

\footnotetext{
${ }^{2}$ Of course many policies focus on distribution of scarce resources, but we believe there is value in the distinction between groups seeking short term material gains, and those seeking policy changes.
} 
sources might attack not just the government, but other rebel groups in order to increase their abilities to control rents or lootable resources. Ideological motivation could drive groups to attack the government in hopes of either toppling the government in order to directly control policy or attacking to impose costs and indirectly obtain policy concessions. Ideologically motivated groups might also attack rebel groups that draw support from different sections of society in order to shift support away from challenger groups in a territory. Similarly, the government also has a number of incentives to attack rebel groups - attacking strong rebel groups reduces the likelihood those groups can defeat the government, but governments also attack to control resources and suppress challengers' abilities to interact violently (through predation) or nonviolently (through public goods provision) with the civilian population.

In order to attack other groups, rebels rely on the ability to mobilize resources. They can do this by mobilizing or taxing the civilian population (Kalyvas, 2006) or through the sale of so called "lootable" goods like alluvial diamonds, narcotics, or tropical timber (Ross, 2004, Lujala et al., 2005; de Soysa, 2000). Alternatively, they can gain resources from foreign supporters - generally, those that are opposed to the central government (Gleditsch, 2007, Regan, 2002b a).

Armed actors and their actions, driven by their motivations and resources, constitute the civil conflict network. In this network the nodes are the different armed groups - both rebel and government - and the links are battles between armed groups. This network is not static over time. New groups are created, groups split into rivals, and groups demobilize and leave the network. Similarly, groups are not constant in their behavior over time and thus might fight each other in one time period yet fight a common enemy in another.

A stylized representation of a dynamic network is shown below. In Figure 1, the nodes represent armed actors and the ties represent battles between armed actors. The 
graphic highlights several important features relevant to our study. Each panel represents a different phase, or new year, of the conflict. In each year, new armed actors might enter or exit the conflict (i.e., an armed group could stop fighting or dissolve). In the visualization, new entrants are shaded in grey. Second, new ties can form between actors in any period, but ties can also disappear over time. For example, moving from panel 1 to panel 2 we can see that some of the linkages in the first time period no longer appear in the second time period, which indicates that two actors that fought in the first time period are not fighting in the second time period. These features demonstrate the type of information that a network conceptualization of conflict development can provide.

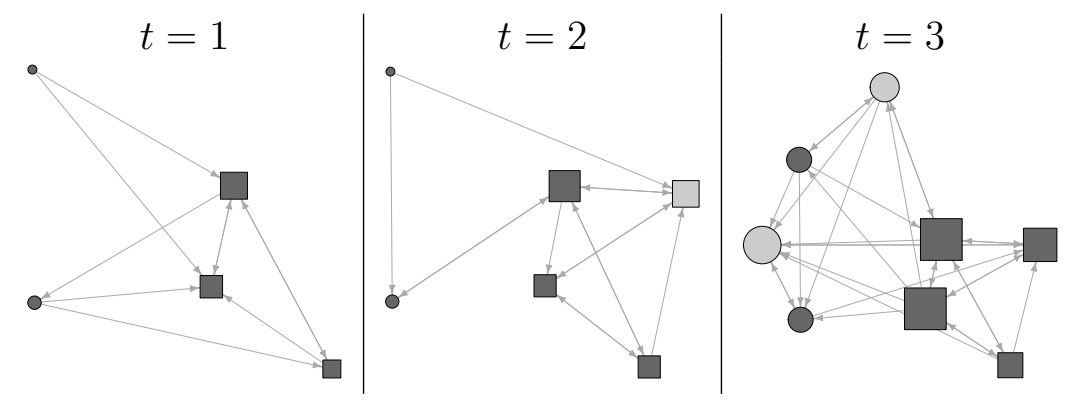

Figure 1: Stylized network graphic depicting changing connections between actors over time, directed linkages, and community clusters.

\section{Network Patterns in Intrastate Conflict}

In this section we explain how dependence patterns echo insights from the literature on rebel groups and civil conflict. We review three main types of dependencies and describe our expectations for how these will influence violence in the civil conflict network.

\section{First Order Dependencies}

In the civil conflict network, some actors are more likely to fight than others due to their group-level characteristics. In the studies of networks, these are called first-order dependencies, and much of the study of rebel group behavior focuses on these kinds of 
factors ${ }^{3}$ In particular, ceteris paribus, certain groups are going to be more likely to attack other groups, and certain groups are going to be more likely to be attacked based on group level attributes.

Many of these first order dependencies stem from a group's motivations or their resources. For example, Weinstein (2007) argues that rebel groups with more ideologically motivated followers are thought to be less violent than groups whose members are motivated by greed. The motivation of group members, then, is a latent, unobserved attribute that accounts for why one rebel group is more prone to attack other groups. Additionally, groups that adhere to an exclusionary ideology - or an ideology that is center-seeking rather than secessionist - will be more likely to attack across the network to advance their agenda. Another example of first order dependence is when a contextual feature of the group makes it more likely to be a target. For instance, if a group possesses territory with valuable natural resources, they are more likely to be attacked by groups that are more motivated by resources.

While some of these factors can be controlled for in the context of a standard regression model, many of them are either contextual or difficult to observe and measure. This creates serious challenges for understanding who fights whom and when during civil conflicts. If two groups fight, it might be because one of the groups is particularly aggressive, or the other group is a particularly appealing target, and failing to account for these first order dependencies will lead to inappropriately assigning credit for the confrontation, and a biased understanding of the sources of violence. A network approach allows us to both appropriately account for actor-level effects, or first-order dependencies, without di-

\footnotetext{
${ }^{3}$ For just a few examples see Weinstein (2007) on organizational structure leading to different levels of violence, Wucherpfennig et al. (2012) on how ethnic power relations makes certain rebel groups more cost tolerant, Buhaug et al. (2009) on rebel capacity and goals.
} 
rectly measuring whether ideology or religion or resources are driving these effects. While measuring this is undoubtedly important and relevant to the study of conflict, testing hypotheses on these characteristics has already been a primary focus of existing theoretical and empirical work. Our aim is to move one step beyond these first order factors to explore relational dimensions of the conflict system.

\section{Second Order Dependencies}

Networks of civil conflict are not created only by the attributes of armed groups, they are also a consequence of armed groups' actions. Condra \& Shapiro (2010) and Lyall (2009) have explored how armed groups affect the tendency of their targets to be violent in the future, and many scholars have examined how rebel groups respond to violence with violence (Kathman \& Wood, 2015). However, few studies have fully explored the consequences of armed group actions (and interactions) to explain fighting during civil wars.

One of the most important ways that conflicts evolve is through reciprocity and retaliation (Moore, 1995) If If one armed group attacks another, it is more likely to be attacked itself. Some of this behavior is not causal. If a latent characteristic of the group leads actor A to attack B, it is also more likely to lead B to attack A. At the same time, dynamics of civilian support can also encourage reciprocity. If a group does not respond to attacks against it, it risks being seen as weak, which can lead to a loss of support from civilians or foreign sponsors. For groups relying on civilians, the need for retaliation can be especially stark, as one of the reasons civilians might support an armed group is for protection from others (Kalyvas, 2006, Valentino et al., 2004).

\footnotetext{
${ }^{4}$ Though reciprocity is an underdeveloped concept as applied to intrastate conflict, reciprocity has been a popular topic in the International Relations literature for decades. For example, see Richardson (1960); Dorff \& Minhas (2017).
} 
Accounting for reciprocity in a conflict network improves our ability to understand many dynamics of civil conflict. It becomes difficult to parse the factors that cause groups to attack and to be targeted if we ignore the fact that some attacks are retaliatory in nature. More generally, understanding reciprocity during civil conflict underscores that conflicts are not static: the actions and reactions passed between groups play a crucial role in shaping the contours of civil conflict.

\section{Third Order Dependencies}

We posit that another form of dependency is relevant to explain conflict in the conflict network. Importantly, there are ways in which the motivations, resources, and actions of groups affect not just their targets, but also unrelated pairs of actors. In the network literature, this is termed "third-order dependencies," where the relationship between A and $\mathrm{B}$ are linked with the relationship between $\mathrm{B}$ and $\mathrm{C}$, and the relation between $\mathrm{A}$ and C. Two particular ways in which this instantiate are homophily and stochastic equivalence.

Armed actors' motivations often lend themselves to homophily or heterophily - the tendency of groups that share a latent trait to interact more or less. Homophily (and heterophily) themselves cause networks to have greater (lesser) levels of transitivity and clusterability. Groups that are primarily ideologically motivated are more likely to attack armed actors that are not ideologically similar (the same holds for ethnic or religious motivations). Similarly, groups that are primarily motivated by desire for material resources are more likely to fight geographically proximate groups rather than distant ones. Accordingly, we should also observe that groups with similar resource bases fight each other in an effort to monopolize access to those resources.

The second type of third order dependency that we expect to influence conflict is stochastic equivalence. Stochastic equivalence captures the tendency for actors to behave similarly in the conflict network. A very straightforward example of this is when groups 
are sponsored by the same foreign actor. In this case, groups are going to be unlikely to fight each other and more likely to fight the government (Bapat \& Bond, 2012). A similar dynamic occurs when rebel groups have actual alliances, whether competitive or otherwise (Zeigler, 2016), and these alliances are formed for strategic reasons Christia (2012). When groups have similar ideological motivations or strategic positions, they are not only unlikely to fight each other, but they are also incentivized to select similar targets. Finally, when ideological groups have secessionist aims, they could be expected to be stochastically equivalent since they would be most likely to fight the central government and not geographically proximate groups.

Taken in concert, we have argued that these types of social structure - actor effects, reciprocity, homophily and stochastic equivalence - influence the likelihood of violence between actors in the conflict network. Importantly, these first, second, and third order effects intuitively reflect theoretical perspectives found in the existing scholarship on civil war and rebel group behavior. Our study unites these two literatures and demonstrates the importance of combining substantive theories of violent behavior with network approaches.

\section{Actor Entry}

An important and under discussed aspect of civil conflict is that actors are not static. Armed groups can enter or exit the civil conflict network at any given time. As Kathman \& Wood 2015, p. 168) have argued "conflict systems are fluid, and competition varies in response to the arrival or exit of violent combat groups...", thus the entry of particularly strong or aggressive groups can have violent ripple effects across the entire conflict network. Perhaps the easiest way a group can affect the conflict network is by directly interacting with other groups, but this is not the limit of their impact. We argue that the presence of a group (call them group A) can increase the likelihood of conflict between two separate groups (group B and C). The two main ways that an actor's entry influences 
the behavior of other groups is by effecting the capabilities and actions of the government and altering the system-wide distribution of resources 5

When a new group enters a conflict it of course forms direct relationships with existing armed groups. These relationships could be 'enemy' relationships if the group is ideologically opposed to existing groups or is a competitor for scarce resources. The new group could be 'friendly' if they are ideologically similar to existing groups or if they have a common enemy (often the government). Or these groups could have a 'neutral' entry for example if the new group is a secessionist movement that faces few competitor rebels groups and primarily fights the government. These types of direct effects - wherein one actor's behavior directly influences another actor - can be accommodated within standard dyadic designs. We argue, however, that in addition to these effects, important indirect processes also emerge from the entry of a new actor.

A new entrant to the system that clashes with the government can significantly increase the level of conflict in the network. Clearly, this is in part because the new violent group is directly involved in conflict, but this group can also spur violence between other armed groups. The entry of a new violent group that targets the government has two possible effects on the conflict network. First, the new group's entry could strain, and ultimately decrease, government resources and capabilities. This weakens the government's ability to provide security and deter violence from other armed groups, even 'neutral' ones. Secondly, when a new armed group successfully defeats government actors in a given

\footnotetext{
${ }^{5}$ Note that the selection of groups who enter an ongoing conflict is going to be different than those groups that are willing to rebel in a peacetime context. In particular, with an ongoing conflict, the opportunity cost for groups to take up arms is lower than it would be at peacetime, and the prospects for survival and success should be higher than if the group faced the consolidated power of the government. Thus, we do not have reason to believe that groups who enter an ongoing conflict will, by their nature, be stronger or more violent, though this should be the subject of cross-national investigation.
} 
region or battle, this harms the government's reputation and makes them appear more vulnerable. Thus, if the government does not want to embolden other challengers (Walter, 2006) it will try to overcompensate for its' loss and demonstrate strength by fighting heavily against armed actors.

The entry of a new group can also affect the actions of other rebels based on those rebels' sources of support. In particular, the entrance of a new group might displace existing groups. This potentially leads groups into conflict with each other over scarce resources and lootable goods. At the same time, when a new group that is particularly strong and aggressive enters the conflict it could ignite a process of outbidding among 'friendly' groups for the support of the civilian population. Civilians might be drawn to support the new 'successful' group, following the dynamics discussed by Bloom (2004), Nemeth (2014), and Toft (2003).

In sum, the entrance of powerful or violent rebel groups into the conflict network can radically change the status quo. The conflict network is not only altered because of the direct relationships the new group forms, but because its entrance will also have an effect on how others actors relate to each other. Specifically, these groups can influence perceptions and capabilities of the government and they also force other rebel groups to be increasingly aggressive in chasing scarce resources. This is most likely to occur when the new group is both strong enough to displace existing groups or challenge the government, and aggressive enough to actually do so. Thus, even when we account for new groups' first order tendencies towards violence, we expect to see their entry associated with a higher level of violence in the overall conflict system.

\section{Case Selection: The Conflict[s] in Nigeria}

To demonstrate the utility of a network approach to studying civil conflict, and to evaluate the effects of the entry of a particularly aggressive actor (Boko Haram), we turn 
to the case of Nigeria. Over the past decade and a half, the people of Nigeria have experienced violence through ethnic and religious group tensions, organized insurgency, and government repression. These complexities make Nigeria a representative case for understanding the phenomena we are interested in, i.e. how network dynamics influence violence between actors. In this section, we describe Nigeria's conflict landscape and summarize the nature of warfare between multiple armed actors, government agents, and civilians.

The year 2000 marks the beginning of a critically tense transition period in Nigeria. Following the 1999 presidential election of Olusegun Obasanjo, Nigeria's 15-year long military dictatorship ends. Meanwhile, a resurgent Islamic political movement consolidates influence in Nigeria's predominantly Muslim northern states. Sharia Law, a penal code in effect for hundreds of years in Nigeria but disbanded in 1960, is re-implemented following the 2000 elections. The implementation of Sharia law then leads to numerous riots and clashes, largely between Muslims and Christians (one clash, in Nigeria's second largest city of Kano, ends with over 100 dead in October of 2001).6

President Obasanjo faces many more violent episodes during his first term. As ChristianMuslim disputes continue in the Northern regions, a tribal war foments in the easterncentral state of Benue. Thousands of people are forced to flee the area, and troops reportedly target unarmed civilians in retaliation for the abduction of nearly 20 soldiers. Continuing Christian-Muslim clashes in the north mark Obasanjo's second term (beginning in 2003) as well as deepening violence in the Niger Delta where militants vie for control of oil production centers. Fighting in the Okere district of Warri occurs between Itsekiris and Urhobos over contentious primary elections held for the Delta South district. Reports state that government forces attempt to suppress violence through execution-style

\footnotetext{
${ }^{6}$ See http://articles.latimes.com/2001/oct/16/news/mn-57819.
} 
killings. The Nigerian Red Cross reports that more than 6,000 people are displaced as result of the fighting: 7

Mohammed Yusuf emerges in the early 2000s as the radical leader of the religious extremist group, the Boko Haram 8 Yusuf spreads an anti-state, anti-elite ideology couched in Sunni Muslim teachings. Conflict in the northern region of Nigeria continues along religious lines, and by 2008 Boko Haram has grown increasingly well organized, operating as a mini-state with institutions, a welfare system, and religious police. Clashes between Boko Haram and state security forces gain momentum as the 2009 uprising begins in the state of Bauchi and spreads to Borno, Yobe, and Kano. These battles are the first sustained conflict between Boko Haram and the government; these clashes culminate in the death of scores of police officers, more than 700 members of Boko Haram, and the capture of Mohammed Yusuf 9

Vice President Goodluck Jonathan succeeds to the presidency following the death of his predecessor in 2010. The death of Yusuf, killed by police in a raid, leads to an intensification of tactics by Boko Haram, including greater violence against civilians. Demonstratively, in December of 2010, Boko Haram bombs kill an estimated 80 people in the central city of Jos. This event sparks a response from opposing Christians leading to roughly 200 more deaths ${ }^{10}$ Attacks on civilians continue and in April of 2014 Boko Haram chooses a target that sparks international condemnation: 276 Chibok schoolgirls. Though this is not the first time that civilians organize against the insurgency's violent tactics, high levels of protest and vigilantism ensue following the children's kidnapping.

\footnotetext{
${ }^{7}$ See https://www.hrw.org/reports/2003/nigeria1103/3.htm for more details.

${ }^{8}$ There is evidence that the early leadership of the movement formed around 2000 or 2002, though in many reports the fully armed, organized, radical group forms closer to the year 2008 following a clash with government forces. See Walker $(2016)$ for details.

${ }^{9}$ See http://edition.cnn.com/2014/06/09/world/boko-haram-fast-facts/.

${ }^{10}$ See http://www .aljazeera.com/news/africa/2013/09/201397155225146644.html.
} 
Battles between Boko Haram, local militant groups, and security forces continue today. While Boko Haram has evolved as perhaps the most well known armed insurgent movement in Nigeria, there are major ethnic militias such as the Urhobo Ethnic Militia that engage in localized battles and groups such as MEND which battle with other armed actors and the government over natural resources. MEND is one of the largest militant groups in the Niger Delta region. The militant organization is expressly concerned with the public and private production of oil in the local area. Despite these important armed actors, Boko Haram's entrance into the conflict network in 2009 has had unique consequences on the stability of the entire region.

Figure 2 shows the spatial distribution of violence in Nigeria from 2001 to 2016, points in red represent Armed Conflict Location and Event Data Project (ACLED) battle events in which Boko Haram is involved (either as the initiator or target) while points in blue designate events that do not involve Boko Haram. Boko Haram's entrance into the system corresponds to an increase in both the level and spread of conflict. The increase in conflict is not attributable to just the violent actions of Boko Haram, instead other actors engage in more conflictual events. Figure 3 further highlights the complexity of Nigeria's conflict and the relevance of relationships between actors: the Fulani Militia is central to the network, as is (understandably) the Nigerian police and military forces. Reciprocal conflictual relations are also visible, such as between the Boko Haram and the Military. 


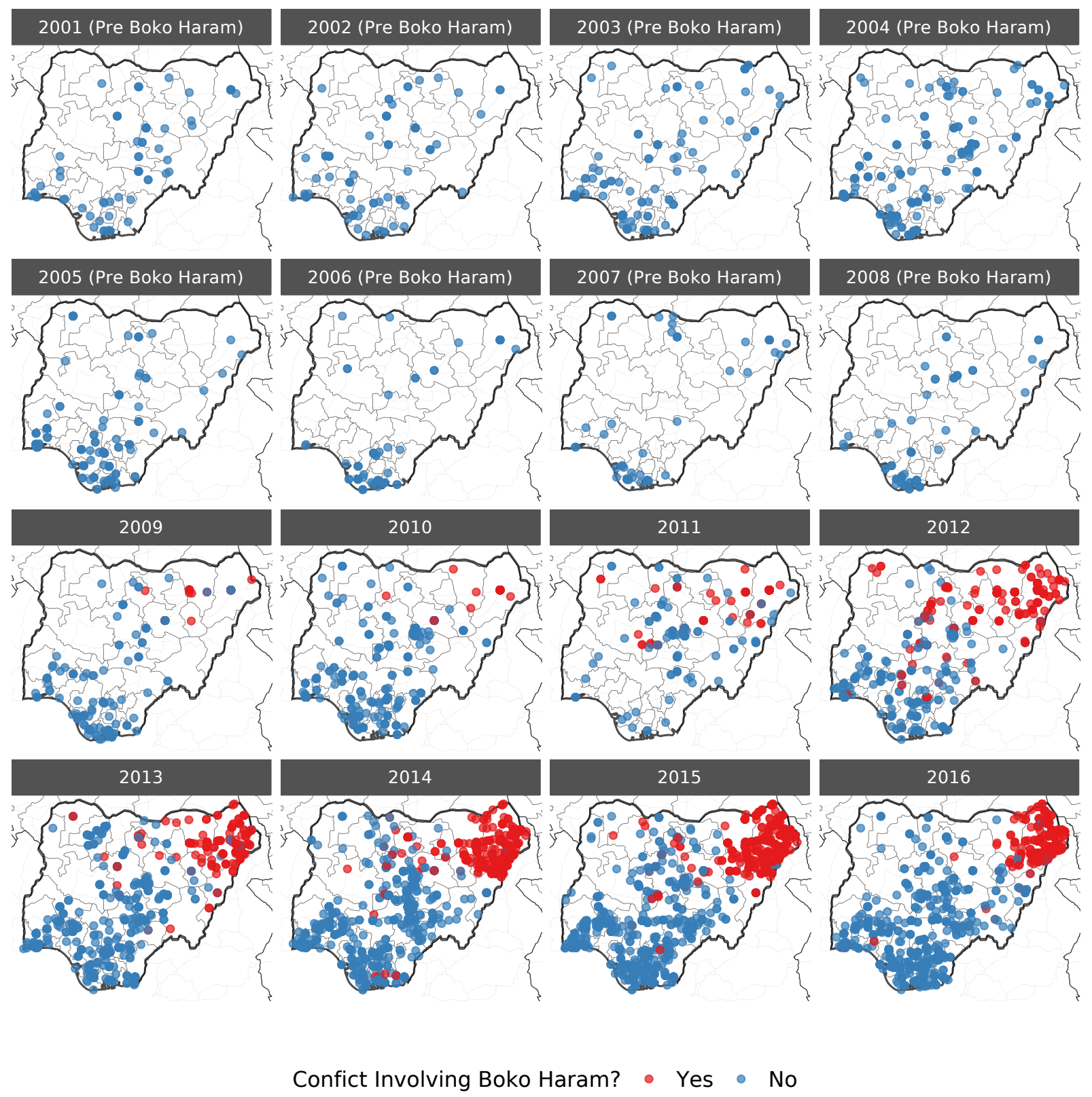

Figure 2: Spatial distribution of conflict in Nigeria from 2001 to 2016. Points colored in blue represent conflict events between sets of actors not including Boko Haram, and points in red events that do involve Boko Haram as either the initiator or target of conflict. 


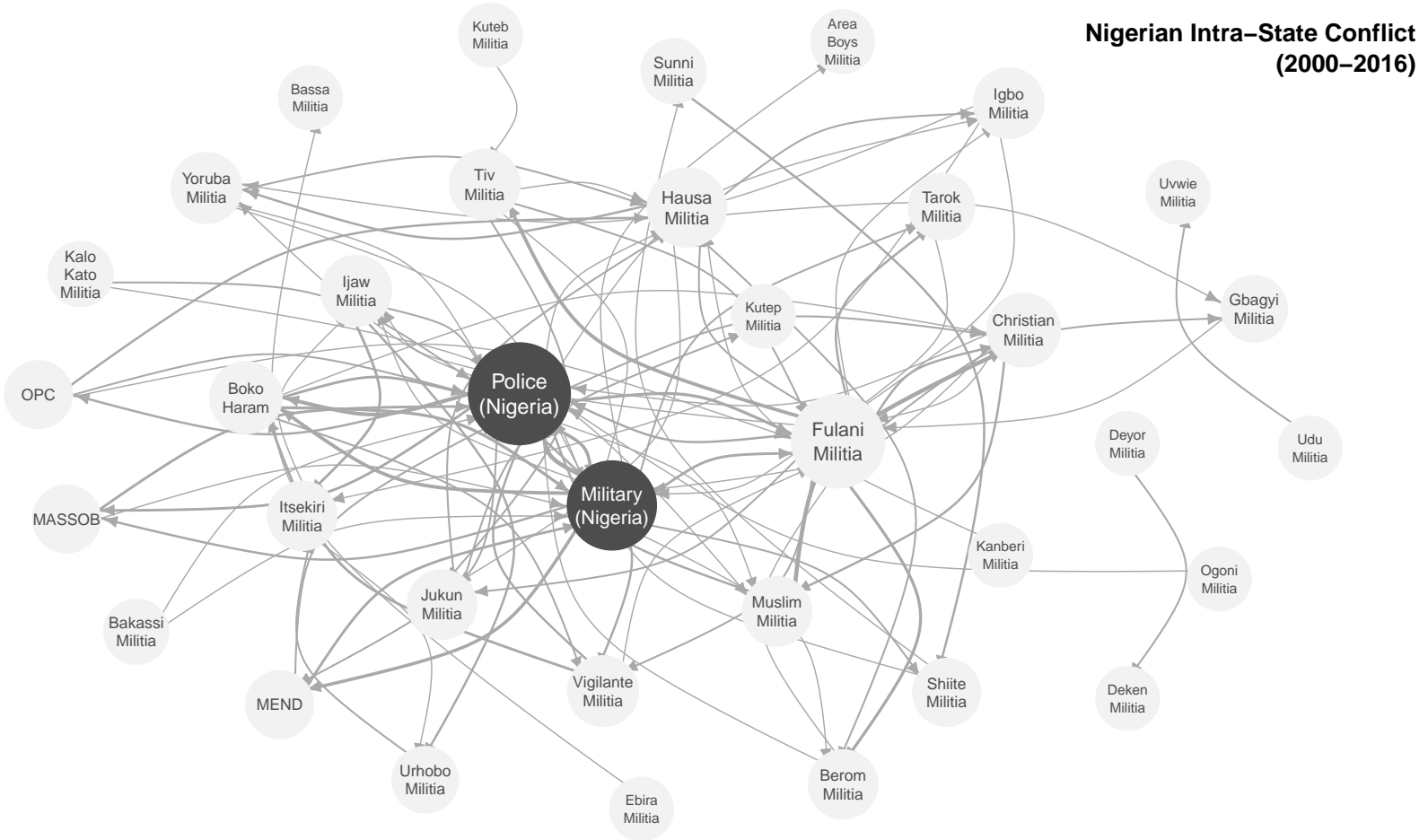

Figure 3: Network graph depicting battles between actors for the entire 2000-2016 time period. Pairs of actors experiencing more conflict have thicker links and arrows indicate direction of ties. 


\section{Data}

To study intrastate conflict patterns in Nigeria we utilize the ACLED dataset developed by Raleigh et al. (2010). This dataset records armed conflict and protest events in over 60 developing countries. ACLED's battles data is used to generate our measure of conflict where $y_{i j, t}=1$ indicates that a conflict occurred when actor $i$ attacked actor $j$ at time $t\left(y_{i j, t}=0\right.$ if no conflict occurred) ${ }^{11} 12$ We focus only on armed groups that are engaged in battles for at least 5 years during the 2000-2016 period, which results in a total of 37 armed groups. 13

The groups included in our battle-data analysis are politically violent actors in Nigeria as defined by the ACLED codebook. Such actors include rebels, militias, and ethnic groups ${ }^{14}$ Additionally, we use secondary resources to confirm the existence of each actor in the data. Overall, the data capture several key types of actors: government armed forces (military and police), insurgent groups (Boko Haram), and ethnic militias (including the

\footnotetext{
${ }^{11}$ In the appendix, we show results when only including battles from ACLED that resulted in at least one battle death. The results when using a fatality threshold and not are similar, thus we focus on the latter for the remainder of this paper.

${ }^{12}$ Some scholars have noted that the ACLED conflict data should be understood as defining symmetric events, since who started a particular battle can at times be difficult to entangle. In the appendix, we show that the results presented in the paper are robust to utilizing a directed or undirected formulation.

${ }^{13}$ In comparison to other data sets used to analyze armed groups, such as the UCDP data, the ACLED data has a higher number of armed actors recorded per year. This seems to be driven in part by the different methodologies underlining each database. For example, the UCDP data records groups that commit a specific threshold of violence during a battle, whereas ACLED data contains information about all groups relevant to all battles, regardless of the number of deaths incurred. For this reason, especially because of our focus on groups entering and leaving the conflict network, our analysis uses the ACLED data.

${ }^{14}$ For detailed definitions of these actors, see the on-line ACLED Africa data codebook maintained at WWW. acleddata.com
} 
Yoruba and Fulani Militias). ${ }^{15}$

The ACLED data also allows us to explore civilians' role in shaping conflict within the Nigerian system. Building on the research agenda motivated by macro-level studies (Tarrow, 1994; Tucker, 2007; Chenoweth \& Stephan, 2011), we investigate the link between civilian mobilization and violence between armed actors at the local level by creating a count of the number of protests/riots led by civilians against a given actor at time $t-1$. While there is a robust debate over what causes civilian victimization ${ }^{16}$ discussion of the consequences of civilian victimization, particularly as they relate to the potential for future conflict has been more limited (Hultman, 2007; Raleigh, 2012). Berman \& Matanock (2015) argue that when rebels groups [governments] kill civilians, other civilians are more [less] likely to share information with the government: information allows the government to carry out attacks against insurgents, and the lack of information makes insurgent attacks less likely. Condra \& Shapiro (2012) find support for this relationship in Iraq. To test for both of these dynamics, we create a count of the number of violent actions that an actor committed against civilians at time $t-1$ and nodal covariates to explain both the probability of an actor sending and receiving a conflictual tie.

\footnotetext{
${ }^{15}$ The country box need not be the boundary for what constitutes a system. Our focus on this paper is in particular understanding the conflict network in Nigeria. However, if one wanted to study the conflict system in the Horn of Africa then the boundary of the system would encompass many countries. Important methodological concerns arise, however, when trying to study such a complex system. Particularly, one would need to carefully consider that the network potentially has a hierarchical structure. Specifically, a small rebel group on the coast of Somalia would be quite unlikely to interact with a rebel group in the south-west of Ethiopia. There are a number of ways of dealing with this type of issue, one could include fixed parameters to account for the geographic location of actors. Alternatively, one could generalize the model that we present here to account for those hierarchies through an additional random effects layer.

${ }^{16}$ See Humphreys \& Weinstein (2006); Downes 2006$) ;$ Kalyvas 2006$) ;$ Prorok \& Appel (2014).
} 
Additionally, we attempt to account for spatial effects in modeling the likelihood of conflict between a particular pair of actors. First, we add a measure of how dispersed a rebel group's activity is across the country. Armed groups whose actions are more dispersed across Nigeria are more likely to come into conflictual contact with others. We include a "Geographic Spread" variable as both a sender and receiver covariate ${ }^{17}$ Second, we add a measure of neighboring conflict to control for the notable literature that has developed explicating the mechanisms through which civil conflict can diffuse between countries ${ }^{18}$ To estimate this effect, we use the ACLED dataset to count the number of conflict events occurring within Nigeria's contiguous neighbors.

We add three other covariates to the model 19 First, we create a control for whether both actors are a part of the government (the Police and Military). We include this control to account for the fact that the probability of an interaction between these two is minimal relative to the other potential dyads in this system. Second, we include a binary variable that takes on the value of one if the following year is an election year and zero otherwise. The election year indicator is included since elections in Nigeria are rarely waged peacefully in the ballot box, but instead are typically followed or preceded by episodes of conflict. Most importantly, to examine the affect that Boko Haram's entrance has had on the level of conflict in this system we include a binary variable that takes on the value of one after the Boko Haram insurgency has begun (in 2009) and zero beforehand ${ }^{20}$

\footnotetext{
${ }^{17}$ For example, to model the spread of group $i$ in period $t$, we calculate this by taking all the events involving group $i$ in the 3 years prior to $t$ and estimate the variance.

${ }^{18}$ See Salehyan \& Gleditsch (2007); Metternich et al. (2017); Braithwaite (2010); Beardsley (2011).

${ }^{19}$ Our covariate selection is limited because the ACLED data does not contain group-level characteristics for each armed group. Due to our time period of interest, we also cannot use other data sets such as the Non-State Actor Data (Cunningham et al. 2009) which ends in 2013.

${ }^{20}$ We choose this date both because 2009 is considered the beginning of the Boko Haram insurgency in most media reports.
} 


\section{Modeling Approach}

To estimate conflict in this system in a way that explicitly models interdependencies between actors, we rely on a network based approach that combines the social relations regression model (SRRM) ${ }^{21}$ and the latent factor model (LFM). Together the SRRM provides a set of additive effects to capture first and second order dependencies, and the latent factor model provides a set of multiplicative effects to model third order dependencies (Minhas et al., 2018). This estimator is referred to as the additive and multiplicative effects (AME) model:

$$
\begin{gathered}
y_{i j, t}=g\left(\theta_{i j, t}\right) \\
\theta_{i j, t}=\boldsymbol{\beta}_{d}^{\top} \mathbf{X}_{i j, t}+\boldsymbol{\beta}_{s}^{\top} \mathbf{X}_{i, t}+\boldsymbol{\beta}_{r}^{\top} \mathbf{X}_{j, t}+e_{i j, t} \\
e_{i j, t}=a_{i}+b_{j}+\epsilon_{i j}+\alpha\left(\mathbf{u}_{i}, \mathbf{v}_{j}\right), \text { where } \\
\alpha\left(\mathbf{u}_{i}, \mathbf{v}_{j}\right)=\mathbf{u}_{i}^{\top} \mathbf{D} \mathbf{v}_{j}=\sum_{k \in K} d_{k} u_{i k} v_{j k}
\end{gathered}
$$

where $y_{i j, t}$ represents whether or not conflict occurred between actor $i$ (the sender) and actor $j$ (the receiver) at time $t$. To model our binary dependent variable we employ a latent variable representation of a probit regression framework, in which we model a latent variable, $\theta_{i j}$, using a set of time varying dyadic $\left(\boldsymbol{\beta}_{d}^{\top} \mathbf{X}_{i j, t}\right)$, sender $\left(\boldsymbol{\beta}_{s}^{\top} \mathbf{X}_{i, t}\right)$, and receiver covariates $\left(\boldsymbol{\beta}_{r}^{\top} \mathbf{X}_{j, t}\right)$.

To be able to assess the effect that the entrance of actors such as Boko Haram have on the Nigerian conflict network, we extend the AME framework to handle networks in which the composition of actors change over time ${ }^{22}$ Typically, when employing a latent

\footnotetext{
${ }^{21}$ For an example application of this model, see Dorff \& Minhas (2017).

${ }^{22}$ This extension is one reason why we choose not to use the Exponential Random Graph Model (ERGM). The ERGM framework requires that the set of actors remain constant over time, and so using
} 
variable framework to longitudinal networks one assumes that the composition of actors is uniform across time, and if the composition is not truly uniform the authors arbitrarily make it so by choosing a select group of actors to study. This is obviously problematic in general and especially in the case of intrastate conflict as rebel groups often emerge and dissolve - meaning that in time $t$ we may have actors $\{i, j, k\}$ in the network, and in time $t+1$ actors $\{i, j, k, l\}$ or just a different set of actors $\{i, j, l\}$. A change in composition can occur in two ways: 1) an actor dissolves after some time, 2) an actor enters the network after some time.

To account for these types of changes to a network, we adjust the estimation procedure of the AME model such that actor observations only contribute to the likelihood of the model once they enter into the network. This procedure is analogous to that adopted by Huisman \& Snijders (2003) for the stochastic actor oriented model (SAOM). They limit the set of actors who can change their outgoing relations (or have incoming relations changed with) to only those that are part of an active set at time $t$. We implement a process for the AME framework in which composition changes are modeled as exogenous events such that actors are allowed to enter and leave the network at fixed time points. The utility of this approach is that the baseline probability of a tie shifts in accordance with the number of active actors in the network at time $t$ and the time-varying covariates already included in the model.

The $a_{i}$ and $b_{j}$ in Equation 1 represent sender and receiver random effects that we incorporate from the SRRM framework:

that framework would require us to either ignore important actors in the network, or treat them as if they were present and non-violent for long periods of time. 


$$
\begin{gathered}
\left\{\left(a_{1}, b_{1}\right), \ldots,\left(a_{n}, b_{n}\right)\right\} \stackrel{\text { iid }}{\sim} N\left(0, \Sigma_{a b}\right) \\
\left\{\left(\epsilon_{i j}, \epsilon_{j i}\right): i \neq j\right\} \stackrel{\text { iid }}{\sim} N\left(0, \Sigma_{\epsilon}\right), \text { where } \\
\Sigma_{a b}=\left(\begin{array}{cc}
\sigma_{a}^{2} & \sigma_{a b} \\
\sigma_{a b} & \sigma_{b}^{2}
\end{array}\right) \quad \Sigma_{\epsilon}=\sigma_{\epsilon}^{2}\left(\begin{array}{ll}
1 & \rho \\
\rho & 1
\end{array}\right)
\end{gathered}
$$

The interpretation of these parameters is straightforward. The sender and receiver random effects are modeled jointly from a multivariate normal distribution to account for correlation in how active an actor is in sending and receiving ties. Heterogeneity in the the sender and receiver effects is captured by $\sigma_{a}^{2}$ and $\sigma_{b}^{2}$, respectively, and $\sigma_{a b}$ describes the linear relationship between these two effects (i.e., whether actors who send [receive] a lot of ties also receive [send] a lot of ties). Beyond these first-order dependencies, second-order dependencies are described by $\sigma_{\epsilon}^{2}$ and a within dyad correlation, or reciprocity, parameter $\rho$.

While the additive effects from the SRRM can deal with first (differing levels of activity across actors) and second order interdependencies (reciprocity), the multiplicative effects are used to deal with third order dependencies. Specifically, this multiplicative effect allows us to model homophily - the tendency of actors with similar characteristics to form strong relationships than those with differing characteristics - and stochastic equivalence, the possibility that two actors $i$ and $j$ will have similar relationships with every other actor in the network. An AME model accounts for these third order effects using the multiplicative term: $\alpha\left(\mathbf{u}_{i}, \mathbf{v}_{j}\right)=\mathbf{u}_{i}^{\top} \mathbf{D} \mathbf{v}_{j}$. This model posits a latent vector of characteristics $\mathbf{u}_{\mathbf{i}}$ and $\mathbf{v}_{\mathbf{j}}$ for each sender $i$ and receiver $j$. The similarity or dissimilarity of these vectors will then influence the likelihood of activity, and provides a representation of third order interdependencies (Minhas et al., 2018). 
The representation of third order interdepedencies is accomplished by a process similar to computing the singular value decomposition (SVD) of the observed network. When taking the SVD we factorize our observed conflict network into the product of three matrices: $\mathbf{U}, \mathbf{D}$, and $\mathbf{V}$. This provides us with a low-dimensional representation of our original conflict network in terms of third order dependence patterns arising in the network. Specifically, values in $\mathbf{U}$ provide a representation of how stochastically equivalent actors are as senders in a network, or more simply put how similar actors are in terms of who they are initiating battles with. For instance, $\hat{\mathbf{u}}_{i} \approx \hat{\mathbf{u}}_{j}$ would indicate that actor $i$ and $j$ initiate battles with similar third parties. $\mathbf{V}$ provide a similar representation but from the perspective of how similar actors are as receivers. The values in $\mathbf{D}$, a diagonal matrix, represent levels of homophily in the network. Parameter estimation in the AME takes place by sampling from the posterior distribution of the full conditionals ${ }^{23}$

\section{Results}

We report the results for the sender, receiver, and dyadic covariates included in the AME model in figure 4$]^{24}$ First, we find little evidence to support the argument that conflict in neighboring countries drives violence between actors in the Nigerian conflict system. We also do not find that actors become particularly more violent during election years. We do, however, find significant evidence for the argument that actors operating across a larger region of Nigeria are likely to come into more conflict with other actors.

\footnotetext{
${ }^{23}$ Further details on the estimation procedure can be found in the Appendix.

${ }^{24}$ Excluded from these results is the dyadic variable for "both are government actors." This is included and has a negative effect in both models, which simply indicates that government actors are unlikely to fight one another. Trace plots for each of these parameter estimates can be found in the appendix.
} 

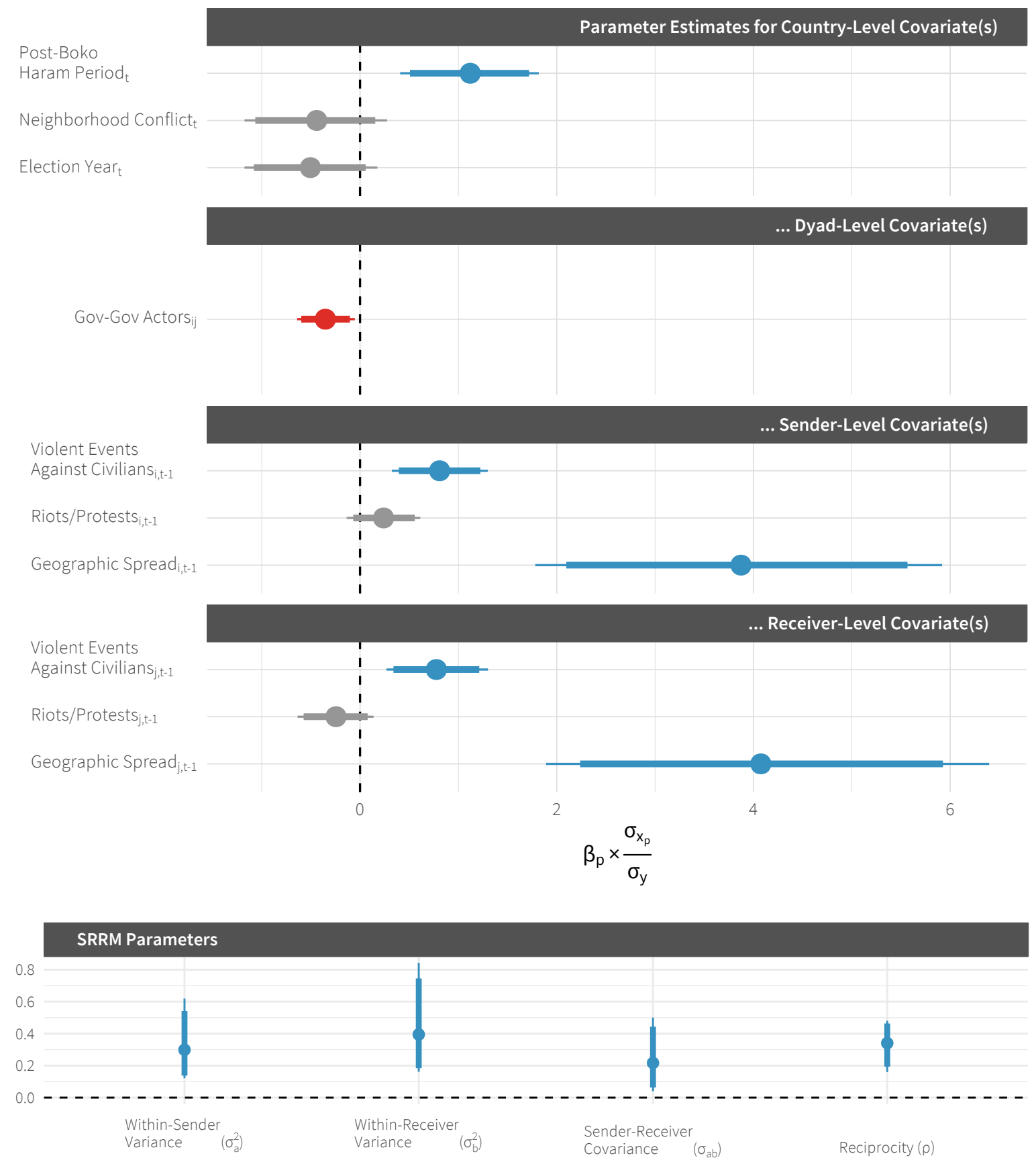

Figure 4: Standardized parameter estimates from AME model. Points represent average value of parameters, thicker line represents the $90 \%$ credible interval, and thinner line the $95 \%$. 
We see a non-trivial relationship between violence against civilians and participation in a greater number of battles. Targeting civilians is linked both to a higher likelihood of engaging in violence against other military groups, and a higher likelihood of being targeted by other military groups ${ }^{25}$ Moving from the $2.5 \%$ ile of violence against civilians to the $97.5 \%$ ile (moving from no violence to 17 attacks), while all other variables are held at their measure of central tendency ${ }^{26}$ increases the risk of starting a battle by the perpetrator by a factor of about 1.58 , and the risk of being targeted for a battle by about 1.55. We cannot causally say that these are the result of violence against civilians, but the fact that the relationship holds even in a mixed-effects model (and one that accounts for network dependencies) is suggestive. Further, anecdotal evidence maintains a similar story. For example, the Óodua People's Congress (OPC), an organization active in the southwest of Nigeria organized to protect the Yoruba ethnic group, is known to engage in two primary modes of conflict: large-scale ethnic battles that directly result in mass casualties to both rivals and civilians, and smaller-scale episodes wherein the OPC targets the civilian base of rival groups.

In the case of this Nigerian conflict network, there is no evidence of a link between civilian protests and the occurrence of a conflict event. There are a number of possible reasons for this null finding: the protest data we use might contain uncertainty about the targets of the protest, some protests might agitate towards greater military involvementsuch as the "Bring Back Our Girls" protests pushing for the government to confront Boko Haram-while other protests might be against violence, or different actors might respond

\footnotetext{
${ }^{25}$ This effect holds even if we leave government actors out of the network or add in binary sender and receiver controls for government actors. See the appendix for details.

${ }^{26}$ We held whether the dyad was in the Post-Boko Haram period, the presence of neighboring conflicts, whether it was a governmental dyad, and whether it was an election year at their median, all other variables, as well as the random and multiplicative effects at their mean level.
} 
to protest in divergent ways.

Finally, we examine the effect of the Boko Haram insurgency on the level of conflict in the system and find a clear increase in violence in the years that follow Boko Haram's entry 27 With all other variables held at their measure of central tendency, a battle between any of the dyads in the system is about 2.82 times as likely in the period after the entrance of Boko Haram as it was before their entrance. Again this is not just the effect of Boko Haram's propensity to target and be targeted in battles, as those first order effects are accounted for in the AME model. The Boko Haram Insurgency is associated with an increase in conflicts even in the dyads that do not contain Boko Haram.

We plot variance parameters from the SRRM in the bottom of figure 4 By looking at the sender and receiver heterogeneity estimates $\left(\sigma_{a}^{2}, \sigma_{b}^{2}\right)$, we see significant first order effects-different actors not only have different baseline levels of conflict, but the variance changes too. We also see a moderate value for $\sigma_{a b}$ indicating that actors which initiate more conflictual links also receive more conflictual links in return. Relatedly, the positive value for $\rho$ indicates that actors whom receive a conflict from a particular sender reciprocate that conflictual behavior. The fact that each of these variance parameters is positive and significantly greater than zero indicates that the assumption of observational independence relied on by standard generalized linear models (GLM) are violated in this dyadic conflict dataset.

\section{Boko Haram's Entrance}

In figure 5, we show that there is both more intense and more widespread conflict with the beginning of Boko Haram's uprising. In this visualization, we shade dyadic re-

\footnotetext{
${ }^{27}$ We find this effect to hold when estimating the model using a temporal exponential random graph model (TERGM) as well - results are presented in the appendix. TERGMs have been used in the past to model instance of interstate conflict (e.g., Cranmer \& Desmarais, 2011).
} 
lationships that experience more conflict after the beginning of Boko Haram's insurgency in blue, those that saw less in red, and those that stay the same in green. Interestingly, much of this conflict does not actually involve Boko Haram. Their conflict is predominantly against the Nigerian Police and Military forces, and yet after their entrance we also see increases in conflict between other groups, and in regions of the country where Boko Haram is not present.

The uptick in conflict after 2009 is most consistent with a logic of multiple rebel groups strategically interacting with the government. Other rebel groups are able to witness Boko Haram's success against the government, and this increases their beliefs that they can challenge the government successfully (or, as Fjelde \& Nilsson (2012) argue, fight each other due to governmental weakness). At the same time, if the government is unsuccessful against Boko Haram, they are incentivized to prove their continued effectiveness against other groups who try to deter future challenges. After Boko Haram's entry in 2009 we see increased attacks between rebel groups, and increased attacks by those groups against the government, but we also see increased attacks by the government-consistent with this logic.

The effect of Boko Haram's entrance underscores the need for a networked approach to intrastate conflict. A standard approach to intrastate conflict, which focuses on the government-rebel dyads, or in particularly ambitious cases, also looks at rebel-rebel dyads, would capture Boko Haram's direct effect on conflict, but it would miss this indirect effect on the conflict system. This echoes our earlier statements in our introduction: to ignore the interdependent nature of fighting is to misunderstand the conflict as a whole.

\section{Network Dependencies}

We use a network model to understand the Nigeria conflict system not just because it can give more precise parameter estimates, but also because it aids in understanding 


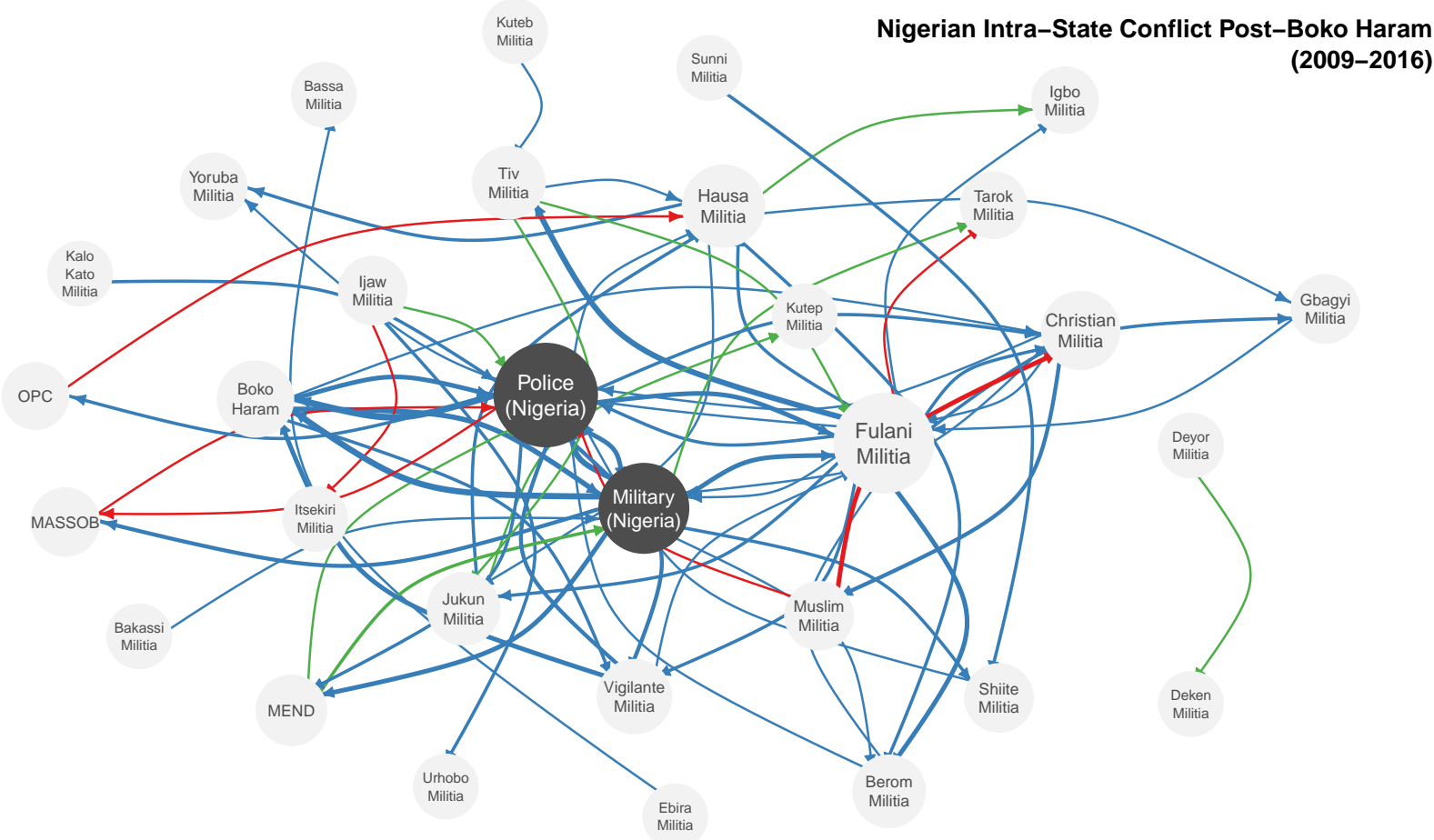

Figure 5: Conflict network 2009-2016. Pairs with more conflict have larger links. Government groups are in black, all other groups are in grey. Blue links indicate more interactions in the 2009-2016 period than in the 2000-2008 period, red indicates less, green no change.

the interdependencies among the actors in the network. Such an approach allows us to infer actor relationships that are typically unobservable. We depict the sender $\left(\hat{a}_{i}\right)$ and receiver $\left(\hat{b}_{j}\right)$ random effects in figure 6 . 


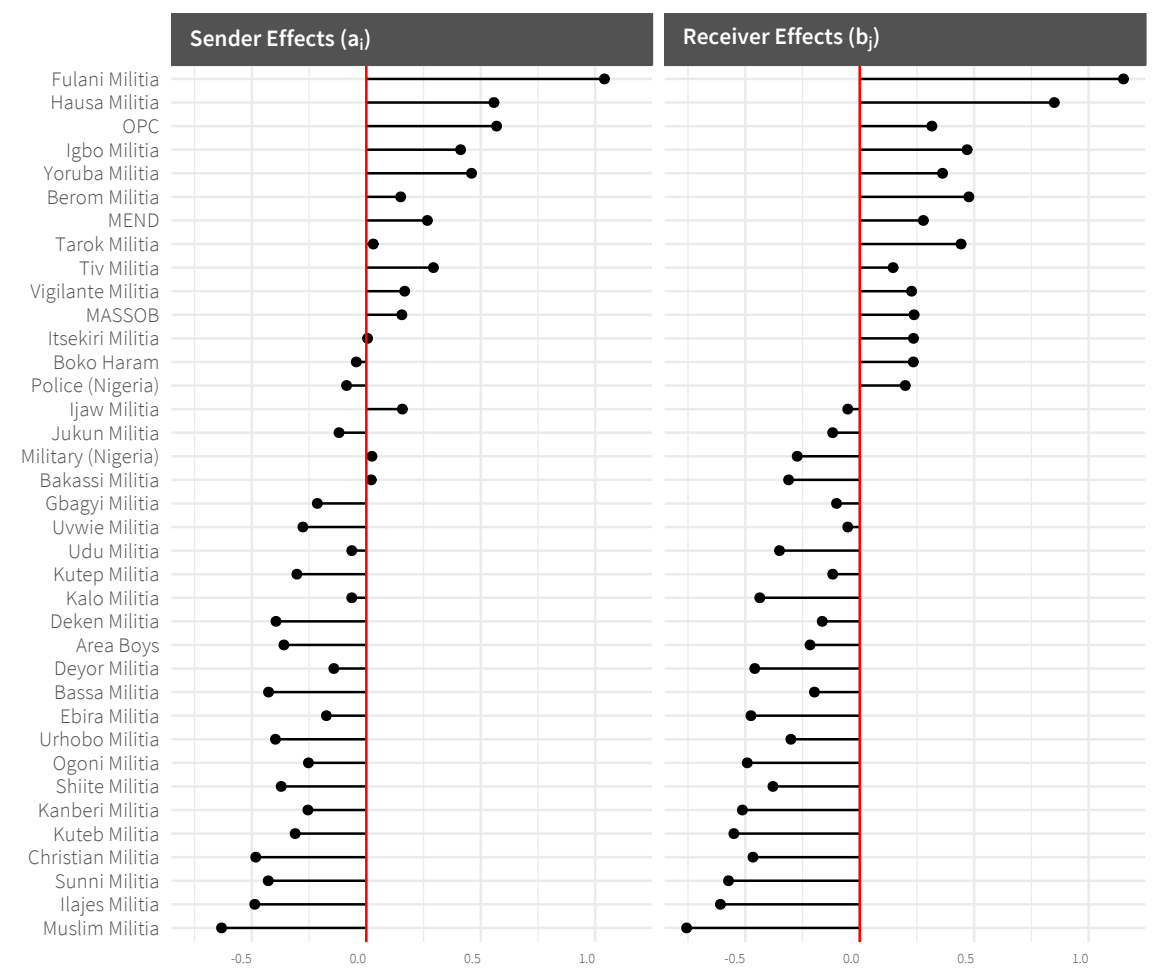

Figure 6: Sender and receiver random effect estimates.

This figure shows which actors are more (and less) violent than would be predicted by just accounting for the exogenous covariates we reviewed in the previous section. We can see, for example, that Boko Haram actually has a random sender effect that is approximately zero, implying that once we account for their high tendency to target civilians and the secular increase in violence that followed their entry into the conflict the model is able to accurately predict the group's tendency towards initiating conflict. On the other hand, actors like the Fulani and Hausa militias have notably positive sender and receiver effects (and the Christian and Muslim Militias have notably negative effects). This gives us cause to believe that the exogenous covariates included in the model are not fully able to explain the behavior of these groups. The implication of this is that there are other latent characteristics possessed by these groups that make them more likely to send and receive conflict. At the same time, an advantage of this approach over a traditional 
GLM analysis is that we are able to easily visualize for which groups our model is falling short.

Figure 7 shows the directions of actors' latent factors for both sending, left panel, and receiving violence, right panel. The directions of $\hat{u}_{i}$ 's (for sending conflict) and $\hat{v}_{i}$ 's (for receiving conflict) are noted in blue and red, respectively. The size of the label assigned to the points is a function of the magnitude of the vectors. The purpose of this figure is to discern groups of actors that are more similar to each other in terms of whom they send conflict to (left panel) or receive conflict from (right). Actor similarity here results from third order dependence patterns - specifically, homophily and stochastic equivalence - that remain after accounting for the other parameters estimated by the model.

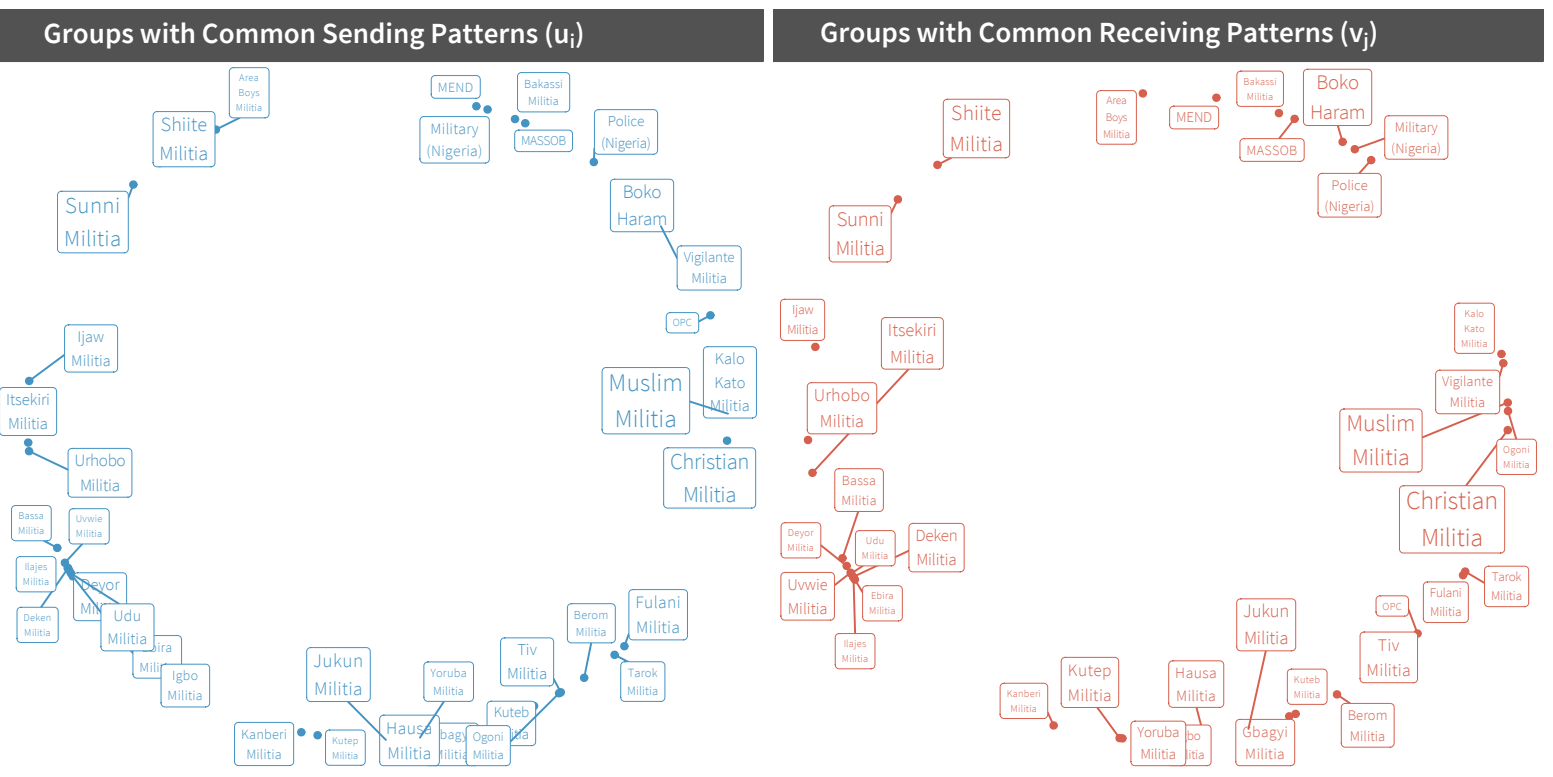

Figure 7: Visualization of multiplicative effects.

By using an AME approach, we are able to better identify previously unobservable patterns of conflict in Nigeria. For example the cluster involving Boko Haram, MASSOB, and MEND is an example of stochastic equivalence: in particular these parties, though spatially heterogeneous, are each predominantly engaged in fighting with the Nigerian 
military and police for control of territory (the Niger Delta for MEND, the state of Biafra for MASSOB, and the North West for Boko Haram). We also find certain groups of actors who are not just more likely to fight common third parties, but they are also more likely to fight each other: for prominent examples of this we can see the proximity between the Sunni and Shiite militias, or the Christian and Muslim militias. Additionally, groups in the bottom of figure 7 such as the Fulani, Tiv, Berom, and Kuteb militias each tend to predominantly operate in the Middle Belt of Nigeria, and form geographically concentrated conflict clusters in which each group initiates or receives conflict with one another - this is an example of a set of homophilous relations.

\section{Out-of-Sample Performance Analysis}

By accounting for exogenous and network dependent patterns that generate conflict systems we are able to better account for the data generating process underlying relational data structures. To show that this is the case, we examine whether our approach achieves better predictive performance in an out-of-sample context than traditional dyadic models. Given that our model is more complex than a GLM, we would expect it to do better insample, but inclusion of more parameters will only improve performance out-of-sample if these parameters are helping us to better capture the underlying data generating process. To evaluate our model, we use a cross-validation procedure where we randomly divide our data into $k$ groups, estimate model parameters without observations from a group, and then predict those excluded observations from the estimated parameters Minhas et al. 2018).

We set a number of benchmarks for comparison. First we compare the AME model to a GLM model using the same covariates to show the effect of accounting for network dependencies on predicting conflict. We supplement this with an alternative GLM that includes not just these covariates, but also a lagged dependent variable and a lagged 
reciprocity term $\sqrt{28}$ The lagged dependent variable is the equivalent of saying that conflict and peace are relatively likely to persist between dyads, while the inclusion of a lagged reciprocity term in a GLM framework is a simple way to account for retaliatory strikes.
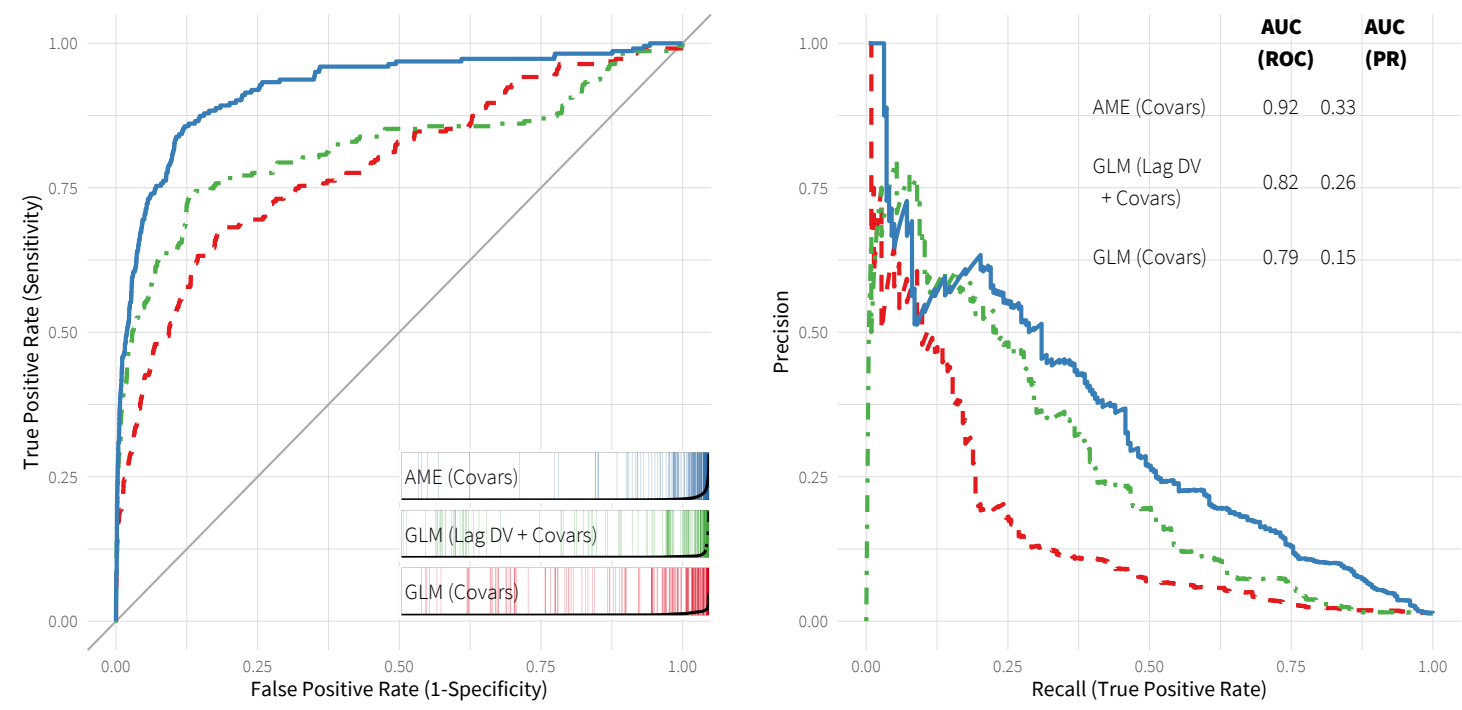

Figure 8: Assessments of out-of-sample predictive performance using ROC curves, separation plots, and PR curves. AUC statistics are provided as well for both curves. In each curve, the AME model is in blue, the GLM with lagged DV and covariates is in green, the GLM with only covariates is in red.

We utilize three performance criterions to compare the models: Receiver Operator Characteristic (ROC) curves, Precision Recall (PR) curves, and separation plots. ROC curves look at the trade-off between true positive rates and false positive rates at different thresholds of classification. ROC curves can be problematic for analyzing conflict because conflict is relatively rare at the dyadic level. If peace is common, even a poor model will have a very low False Positive Rate. PR curves, on the other hand, examine the tradeoffs between the percentage of conflicts a model predicts, and the percentage of predicted conflicts which occur. Lastly, we use separation plots to provide an intuitive visualization

\footnotetext{
${ }^{28}$ In the appendix, we also show that our approach outperforms a random forest classifier in its ability to predict conflictual events out-of-sample.
} 
of the accuracy of our predictions. All of the models' performance out-of-sample by these metrics are displayed in figure 8. The AME model with covariates is the best performing model out-of-sample in all cases. This model outperforms each of the GLM variants by a notable margin $\sqrt{29}$

\section{Discussion: Intrastate Conflict as a Dynamic Network}

Intrastate conflicts are often more complex than Manichaean struggles between the government and a unified opposition. More and more, they involve a number of actors operating in an environment where interactions are interdependent. In the case of Nigeria, our network approach does better at predicting "who fights whom and when" out-ofsample than extant approaches. The improved predictive performance of our network approach is a result of the fact that there is significant network based structure underlying the Nigerian conflict system. Importantly, this network structure is more than just a useful part of our modeling approach; it actually helps to explain who fights who during conflict.

In our study, first order dependencies reveal that ethnic-militias in central Nigeria are more violent than expected. Specifically, the Fulani militia is particularly more active in engaging in battles than the exogenous sender, receiver, and dyadic variables in our model would predict. This highlights the opportunity for further research into understanding what latent attributes may drive such inflated conflictual behavior. Second order effects, such as reciprocity, also reveal important insights. The presence of reciprocity in battles, and the consistent relationship between civilian victimization and conflict, confirm our expectation that the interactions between actors matter at least as much as their mere

\footnotetext{
${ }^{29}$ We also test model forecasting ability temporally by dividing the data into a training and test set, where the test set corresponds to the last period in the dataset that we have available. Results for this analysis are shown in the appendix and here again we find that our network based approach has better out-of-sample predictive performance than alternative approaches.
} 
characteristics. Further our visualization of the multiplicative effects captures third order dependencies and shows strong evidence that actors in this system form various communities of conflict. Each of these dependencies points to the fact that there is an underlying structure to the set of dyadic interactions that we observe in this network even after accounting for the effects of exogenous covariates. Since these patterns play a role in the data-generating process of intrastate conflict, our approach out-performs more traditional frameworks that ignore such dependencies.

Additionally, because we are able to estimate a network model in which actor composition changes over time, we can assess the impact that particular actors such as Boko Haram have on the system. We find that the entrance of this single actor profoundly influenced the occurrence of battles across the system. Boko Haram's entrance does not simply increase conflict directly, it also is associated with a marked rise in violence in the dyads that do not include Boko Haram.

A limitation of this study, however, is that this is a network analysis of a single conflict. For example, our findings that civilian riots and protests affect the course of a conflict are not necessarily generalizable to cases beyond Nigeria and the specific time span studied here. To investigate the cross-national implications of our findings we need an approach that accounts for the fact that conflict networks can span multiple countries over time. In future work, we will build on extant tensor based network approaches to explore the affect of exogenous covariates across multiple countries (e.g., Boccaletti et al., 2014; Schein et al. 2015, Minhas et al., 2016).

\section{Conclusion}

These contributions are not without their limitations. While our study affirms the utility of ACLED data efforts, more actor-level characteristics are needed to fully engage the rich literature on civil war dynamics. Such data would enable even more precise in- 
vestigation of covariates of interest for determining changes in rebel group behavior over time. Second, though our study has revealed meaningful findings with respect to key covariates such as civilian victimization, more research is needed to explore the generalizability of such results. Even after controlling for network related dependencies within this system, we find that actors who target civilians are more likely to receive and send conflict themselves. Relatedly, we find little evidence that civilian led protest against a particular actor changes that actor's likelihood in initiating conflict. The findings with regards to the role of civilian victimization and civilian riots/protests might not generalize beyond the Nigerian case. Nigeria may be unique for several reasons, its 150 million people are divided almost equally between Muslims and Christians. Further, Nigerians split into even finer divisions based on tribe, of which there are over 200 in the country. Future research should compare and contrast these findings beyond the Nigerian case to better illuminate the networked nature of civilian mobilization in conflict environments. We hope this study motivates future work that more fully considers the relationship between the behavior of armed actors and civilian behavior in complex settings.

Similarly, while our study has found consistent evidence that the entrance of Boko Haram altered the trajectory of the Nigerian conflict, more research is needed to fully understand the effects of group entry. This future research agenda is two-fold. First, we need to understand the decision of armed actors to join an ongoing civil conflict, why they enter and how they differ from groups willing to start a civil conflict. More importantly, we need to understand why some actors have stronger effects on shaping interactions across a network than others. Doing so will allow us to understand when the entrance of a particular group is going to destabilize a network or greatly escalate the level of violence.

Our study has embraced the complexity of multi-actor conflicts, rather than discounted it. We have shown that network dynamics help explain the occurrence of violence between groups over time, even as actors enter and exit the conflict. We have demonstrated how 
key, violent actors can increase violence across the network system. Additionally, our approach achieves a longstanding goal of conflict studies: to accurately predict violence over time. And, importantly, our study offers meaningful insights into how conflict scholars can effectively pair methodological innovations in the study of interdependence and network analysis to expand our understanding of civil conflict. 
Acemoglu, Daron \& James A Robinson (2001) A theory of political transitions. American Economic Review 91: 938-963.

Akcinaroglu, Seden (2012) Rebel interdependencies and civil war outcomes. Journal of Conflict Resolution 56(5): 879-903.

Alesma, Adriaan (2015) The farc's biggest fear: Colombia's paramilitary groups. Colombia Reports: 10 July (https://colombiareports.com/ the-farcs-biggest-fear-colombias-paramilitary-groups/).

Bapat, Navin A \& Kanisha D Bond (2012) Alliances between militant groups. British Journal of Political Science 42(4): 793-824.

Beardsley, Kyle (2011) Peacekeeping and the contagion of armed conflict. The Journal of Politics 73(04): 1051-1064.

Beauchamp, Zack (2014) The kurdish war: How isis and syria are reigniting an old conflict in turkey. Vox: 15 October (https://www.vox.com/2014/10/15/6977599/ pkk-turkey-isis-kobane-syria).

Berman, Eli \& Aila M Matanock (2015) The empiricists' insurgency. Annual Review of Political Science 18: 443-464.

Bloom, Mia M (2004) Palestinian suicide bombing: Public support, market share, and outbidding. Political Science Quarterly 119(1): 61-88.

Boccaletti, Stefano; G. Bianconi; R. Criado; Charo I. D Genio; J. Gómez-Gardeñes; M. Romance; I. Sendina-Nadal; Z. Wang \& M Zanin (2014) The structure and dynamics of multilayer networks. Physics Reports 544(1): 1-122.

Bodea, Cristina \& Ibrahim Elbadawi (2007) Riots, coups and civil war: Revisiting the greed and grievance debate. 
Braithwaite, Alex (2010) Resisting infection: How state capacity conditions conflict contagion. Journal of Peace Research 47(3): 311-319.

Bueno de Mesquita, Bruce; Alastair Smith; Randolph M Siverson \& James D Morrow (2005) The Logic of Political Survival. Cambridge, Mass: MIT Press.

Buhaug, Halvard; Scott Gates \& Päivi Lujala (2009) Geography, rebel capacity, and the duration of civil conflict. Journal of Conflict Resolution 53(4): 544-569.

Chenoweth, Erica \& Maria J Stephan (2011) Why civil resistance works: The strategic logic of nonviolent conflict. Columbia University Press.

Christia, Fotini (2012) Alliance formation in civil wars. Cambridge University Press.

Collier, Paul \& Anke Hoeffler (2004) Greed and grievance in civil war. Oxford Economic Papers 56: 563-595.

Condra, L.N. \& J.N. Shapiro (2010) Who takes the blame? The strategic effects of collateral damage. American Journal of Political Science.

Condra, Luke N \& Jacob N Shapiro (2012) Who takes the blame? The strategic effects of collateral damage. American Journal of Political Science 56(1): 167-187.

Cranmer, Skyler \& Bruce A Desmarais (2011) Inferential network analysis with exponential random graph models. Political Analysis 19(1): 66-86.

Cunningham, David; Kristian S Gleditsch \& Idean Salehyan (2009) It takes two: A dyadic analysis of civil war duration and outcome. Journal of Conflict Resolution 53(4): 570597.

Cunningham, David E (2006) Veto players and civil war duration. American Journal of Political Science 50(4): 875-892. 
de Soysa, Indra (2000) The resource curse: Are civil wars driven by rapacity or paucity? In: FIND PLEASE (ed.) Greed and Grievance: Economic Agendas in Civil Wars. Boulder, Colorado, USA: Lynne Rienner chapter FINDIT, , FINDIT.

Dorff, Cassy \& Shahryar Minhas (2017) When do states say uncle? network dependence and sanction compliance. International Interactions 43(4): 563-588.

Downes, A.B. (2006) Desperate times, desperate measures: The causes of civilian victimization in war. International Security 30(4): 152-195.

Fjelde, Hanne \& Desirée Nilsson (2012) Rebels against rebels: Explaining violence between rebel groups. The Journal of Conflict Resolution 56(4): 604-628.

Gleditsch, Kristian S (2007) Transnational dimensions of civil war. Journal of Peace Research 44(3): 293-309.

Goemans, Hein E (2000) Fighting for Survival: The Fate of Leaders and the Duration of War. Journal of Conflict Resolution 44(5): 555-579.

Gurr, Ted R (1970) Why Men Rebel. Princeton, NJ: Princeton University Press.

Harbom, Lotta; Erik Melander \& Peter Wallensteen (2008) Dyadic dimensions of armed conflict, 1946-2007. Journal of Peace Research 45(5): 697-710.

Huisman, Mark \& Tom A Snijders (2003) Statistical analysis of longitudinal network data with changing composition. Sociological methods \&3 research 32(2): 253-287.

Hultman, Lisa (2007) Battle losses and rebel violence: Raising the costs for fighting. Terrorism and Political Violence 19(2): 205-222.

Humphreys, Macartan \& Jeremy M Weinstein (2006) Handling and manhandling civilians in civil war. American Political Science Review 100(3): 429-447. 
Kalyvas, Stathis (2006) The Logic of Violence in Civil War. New York: Cambridge University Press.

Kathman, Jacob D \& Reed M Wood (2015) Competing for the crown: Inter-rebel competition and civilian targeting in civil war. Political Research Quarterly 68(1): 167-179.

La Rosa, Lucy \& David Shirk (2018). The new generation: Mexico's emerging organized crime threat. Technical report Justice in Mexico.

Lujala, Päivi; Nils P Gleditsch \& Elisabeth Gilmore (2005) A diamond curse? Civil war and a lootable resource. Journal of Conflict Resolution 49: 538-562.

Lyall, Jason (2009) Does Indiscriminate Violence Incite Insurgent Attacks?: Evidence from Chechnya. Journal of Conflict Resolution 53(3): 331-362.

Metternich, Nils; Shahryar Minhas \& Michael Ward (2017) Firewall? Or wall on fire? A unified framework of conflict contagion and the role of ethnic exclusion. Journal of Conflict Resolution 61(6): 1151-1173.

Minhas, Shahryar; Peter D Hoff \& Michael D Ward (2016) A new approach to analyzing coevolving longitudinal networks in international relations. Journal of Peace Research 53(3): 491-505.

Minhas, Shahryar; Peter D Hoff \& Michael D Ward (2018) Inferential approaches for network analysis: AMEN for latent factor models. Political Analysis.

URL: https://arxiv.org/abs/1611.00460

Moore, Will H (1995) Action-reaction or rational expectations? reciprocity and the domestic-international conflict nexus during the "rhodesia problem". Journal of Conflict Resolution 39(1): 129-167. 
Nemeth, Stephen C (2014) The effect of competition on terrorist group operations. Journal of Conflict Resolution 58(2): 336-362.

Prorok, Alyssa K \& Benjamin J Appel (2014) Compliance with international humanitarian law: Democratic third parties and civilian targeting in interstate war. Journal of Conflict Resolution 58(4): 713-740.

Raleigh, Clionadh (2012) Violence against civilians: A disaggregated analysis. International Interactions 38(4): 462-481.

Raleigh, Clionadh; Andrew Linke; Håvard Hegre \& Joakim Karlsen (2010) Introducing ACLED: An armed conflict location and event dataset special data feature. Journal of Peace Research 47(5): 651-660.

Regan, P.M. \& D. Norton (2005) Greed, grievance, and mobilization in civil wars. Journal of Conflict Resolution 49(3): 319-336.

Regan, Patrick M (2002a) Civil wars and foreign powers: Outside intervention in intrastate conflict. Ann Arbor: University of Michigan Press.

Regan, Patrick M (2002b) Third party interventions and the duration of intrastate conflicts. Journal of Conflict Resolution 46(1): 55-73.

Richardson, Lewis F (1960) Arms and Insecurity. Chicago and Pittsburgh, PA: Quadrangle/Boxwood.

Ross, Michael (2004) How do natural resources influence civil war? Evidence from thirteen cases. International Organization 58(1): 35-67.

Salehyan, Idean \& Kristian S Gleditsch (2007) Refugees and the spread of civil war. International Organization 60(2): 335-366. 
Schein, Aaron; John Paisley; David M Blei \& Hanna Wallach (2015). Bayesian poisson tensor factorization for inferring multilateral relations from sparse dyadic event counts. In: Proceedings of the 21th ACM SIGKDD International Conference on Knowledge Discovery and Data Mining, 1045-1054. ACM.

Schmitt, Eric (2018) Battle to stamp out isis in syria gains new momentum, but threats remain. New York Times: 30 May (https://www.nytimes.com/2018/05/30/world/ middleeast/isis-syria-battle-kurds-united-states.html).

Tarrow, Sidney (1994) Power in Movement: Social Movements, Collective Action and Politics. Cambridge and New York: Cambridge University Press.

Tilly, Charles (1985) Models and realities of popular collective action. Social research: $717-747$.

Toft, Monica D (2003) The Geography of Ethnic Violence: Identity, Interests, and the Indivisibility of Territory. Princeton, NJ: Princeton University Press.

Tucker, Joshua A (2007) Enough! Electoral fraud, collective action problems, and postCommunist colored revolutions. Perspectives on Politics 5(3): 535-551.

Valentino, Benjamin; Paul Huth \& Dylan Balch-Lindsay (2004) 'draining the sea': Mass killing and guerrilla warfare. International Organization 58(2): 375-407.

Walker, Andrew (2016) 'Eat the Heart of the Infidel': The harrowing of Nigeria and the rise of Boko Haram. London: Hurst and Company.

Walter, Barbara F (2006) Information, uncertainty, and the decision to secede. International Organization 60(1): 105-135.

Weinstein, Jeremy M (2007) Inside rebellion: The politics of insurgent violence. Cambridge: Cambridge University Press. 
Wucherpfennig, Julian; Nils Metternich; L.-E Cederman \& Kristian S Gleditsch (2012) Ethnicity, the state, and the duration of civil wars. World Politics 64(1): 79-115.

Zeigler, Sean M (2016) Competitive alliances and civil war recurrence. International Studies Quarterly 60(1): 24-37.

URL: + http://dx.doi.org/10.1093/isq/sqv002 


\section{Acknowledgements}

We would like to thank our excellent anonymous reviewers for their advice on this manuscript. We also thank Kyle Beardsley, Bethany Lacina, Scott de Marchi, Jacob Montgomery, Betsy Sinclair, Jakana Thomas, Michael Ward, participants at Duke University's Security Peace and Conflict workshop, participants at the University of California - Los Angeles' Center for Population Research workshop, and participants at the Modeling Spatial and Network Interdependencies workshop (ISA 2018) for their helpful comments and insights. While feedback from this community of scholars greatly improved our work, all remaining errors are our own.

\section{Biographical Statement}

Cassy Dorff is an Assistant Professor of Political Science at the University of New Mexico, Albuquerque, NM, 87106, USA.

Max Gallop is a Lecturer of Politics and International Relations at the University of Strathclyde, Glasgow, UK G1 1XQ

Shahryar Minhas is an Assistant Professor of Political Science at Michigan State University, East Lansing, MI 48824, USA 